\title{
AFM tensile test of sub-micron thick DLC film for surface modification in MEMS
}

\author{
Yoshitada Isono $^{1}$ and Takahiro Namazu ${ }^{2}$ \\ 1. Department of Mechanical Engineering, Ritsumeikan University, Shiga, Japan \\ 2. Division of Mechanical System, Himeji Institute of Technology, University of Hyogo, Hyogo, Japan
}

\begin{abstract}
This research focuses on revealing mechanical properties of diamond-like carbon (DLC) films for surface modification in MEMS. New compact tensile tester operating in an atomic force microscope (AFM) was developed for characterization of Young's modulus, Poisson's ratio and fracture strength of DLC films. The DLC films having sub-micron thickness from $0.2 \mu \mathrm{m}$ to $0.5 \mu \mathrm{m}$ were deposited onto microscale single crystal silicon (SCS) specimens by PE-CVD method of the hot cathode PIG discharge type. Young's moduli of the DLC films in AFM tensile tests ranged from $99 \mathrm{GPa}$ to 112 GPa. AFM tensile tests and nano-indentation tests revealed that Poisson's ratio of DLC films ranged from 0.27 to 0.40. Fracture stress of the films also exhibited from $0.5 \mathrm{GPa}$ to $1.1 \mathrm{GPa}$, which depended on the film thickness and deposition condition. SEM observations of fracture surfaces suggested that the fracture initiation of DLC/SCS specimens was induced at the boundary between the film and SCS substrate.
\end{abstract}

Key words: Atomic force microscope, Tensile test, Diamond-like carbon film, Young's modulus, Poisson's ratio, Fracture strength, SEM observation

\section{INTRODUCTION}

Diamond-like carbon (DLC) film is promising coating material because of desirable properties of high hardness, high wear resistance, electrical resistance and chemical inertness [1]-[3]. An overcoat in micro electro mechanical systems (MEMS) is one of the applications of the films for surface modification in MEMS. Understanding mechanical properties as well as tribological properties of DLC films is required for reliable design of the DLC coated MEMS components. Mechanical properties of sub-micron thick DLC films deposited on a substrate have been estimated by nano-indentation test, since the films are usually possessed of substantial intrinsic stress that prohibits self-standing of the films [4]-[6]. The indentation test can be performed easily as compared with the other methods, but cannot estimate Poisson's ratio and fracture strength of films. Tensile test has the distinctive advantages of obtaining a stress-strain relation, directly, so Young's modulus and fracture strength of a specimen can be obtained. If the lateral strain as well as the longitudinal strain of a specimen can be measured during the test, Poisson's ratio can also be evaluated accurately.

The objective of this paper is to propose a new technique for evaluation of mechanical properties of sub-micron thick DLC films. We developed compact tensile tester operating in an atomic force microscope (AFM) to measure longitudinal and lateral elongations at the gauge section of specimens during a tensile test. Not only the tensile test but also nano-indentation test using a diamond indenter was performed to determine Poisson's ratio of the DLC films. Finally, fracture mechanism of DLC coated SCS specimens also discussed in the light of scanning electron microscope (SEM) observations.

\section{EXPERIMENTAL PROCEDURE}

\subsection{Fabrication of DLC/SCS micro-specimen}

Microscale single crystal silicon (SCS) and DLC coated SCS (DLC/SCS) specimens were fabricated by a conventional photolithography technique. Tensile axis of SCS specimens was oriented along the [110] direction in the (001) plane. Fig. 1 shows the fabrication process for the DLC/SCS specimens along with the photograph. A silicon-on-insulator (SOI) wafer with a $19 \mu \mathrm{m}$-thick SCS and a $1 \mu \mathrm{m}$-thick silicon dioxide $\left(\mathrm{SiO}_{2}\right)$ on $400 \mu \mathrm{m}$-thick SCS is employed to prepare all of the specimens (Fig. 1(a)). First, specimen area and grip ends are fabricated simultaneously by anisotropic wet etching with a solution of tetramethyl ammonium hydroxide (TMAH) from back- and topside of the wafer, respectively (Fig. 1(b)). After etching an $\mathrm{SiO}_{2}$ layer on the top surface, DLC films having the thickness of 0.11 to $0.58 \mu \mathrm{m}$ are deposited by plasma-enhanced chemical vapor deposition (PE-CVD) method of the hot cathode penning ionization discharge (PIG) type. The deposition was carried out using acetylene $\left(\mathrm{C}_{2} \mathrm{H}_{2}\right)$ gas under controlling the bias voltages at $-100 \mathrm{~V}$ and $-300 \mathrm{~V}$ (Fig. 1(c)). Subsequently, a photolithographic patterning and dry etching using RIE form the gauge section of specimen (Fig. 1(d)). For SCS specimens of a single layer, the deposition and the RIE processes of DLC film are excluded. Following an $\mathrm{SiO}_{2}$ etching on the back surface, a resist grid pattern is fabricated at the center of the gauge section to be used for direct strain measurement using an AFM cantilever (Fig. 1(e), (f)). SCS tensile specimens having a $19 \mu \mathrm{m}$-thick, a $300 \mu \mathrm{m}$-wide, and $3 \mathrm{~mm}$-length was prepared in this research.

Eight kinds of DLC/SCS specimens were used for 
Table 1 Averaged dimensions of SCS and DLC/SCS specimens along with the deposition condition of DLC films

\begin{tabular}{|c|c|c|c|c|c|c|c|c|c|c|}
\hline \multirow{3}{*}{\multicolumn{2}{|c|}{ Specimen No. }} & Bias & \multirow{2}{*}{\multicolumn{2}{|c|}{ Gas flow rate }} & \multirow{3}{*}{$\begin{array}{c}\begin{array}{c}\text { Discharge } \\
\text { current }\end{array} \\
I_{d}[\mathrm{~A}]\end{array}$} & \multirow{2}{*}{$\begin{array}{c}\text { Deposition } \\
\text { time }\end{array}$} & \multicolumn{2}{|c|}{ Thickness } & \multirow{2}{*}{$\begin{array}{l}\text { Width of } \\
\text { specimen }\end{array}$} & \multirow{2}{*}{$\begin{array}{l}\text { Length of } \\
\text { specimen }\end{array}$} \\
\hline & & voltage & & & & & SCS & DLC & & \\
\hline & & $B_{v}[\mathrm{~V}]$ & $\mathrm{Ar}[\mathrm{ml} / \mathrm{min}$ & $\mathrm{H}_{2}[\mathrm{ml} / \mathrm{min}]$ & & $T_{d}[\mathrm{sec}]$ & $t_{1}[\mu \mathrm{m}]$ & $t_{2}[\mu \mathrm{m}]$ & $w[\mu \mathrm{m}]$ & $l[\mathrm{~mm}]$ \\
\hline$\overline{\overline{\text { SCS }}}$ & & 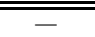 & $\overline{-1}$ & 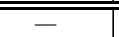 & $\overline{-1-}$ & 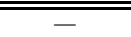 & 19 & - & 300 & $\overline{3}$ \\
\hline \multirow{8}{*}{ DLC/SCS } & $\bar{A}$ & \multirow{4}{*}{-100} & \multirow{4}{*}{10} & \multirow{4}{*}{150} & \multirow{4}{*}{8.6} & 120 & 19 & 0.134 & 300 & 3 \\
\hline & $B$ & & & & & 180 & 19 & 0.299 & 300 & 3 \\
\hline & $C$ & & & & & 240 & 19 & 0.377 & 300 & 3 \\
\hline & $D$ & & & & & 300 & 19 & 0.470 & 300 & 3 \\
\hline & $E$ & \multirow{4}{*}{-300} & \multirow{4}{*}{10} & \multirow{4}{*}{150} & \multirow{4}{*}{8.6} & 150 & 19 & 0.232 & 300 & 3 \\
\hline & $F$ & & & & & 225 & 19 & 0.316 & 300 & 3 \\
\hline & $G$ & & & & & 300 & 19 & 0.418 & 300 & 3 \\
\hline & $H$ & & & & & 375 & 19 & 0.529 & 300 & 3 \\
\hline
\end{tabular}

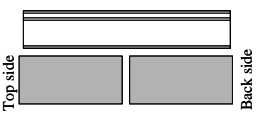

(a) SOI wafer

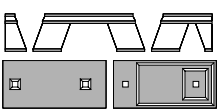

(b) Wet etching of $\mathrm{Si}$

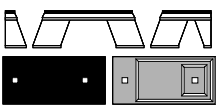

(c) Deposition of DLC

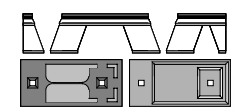

(d) Dry etching of DLC and $\mathrm{Si}$

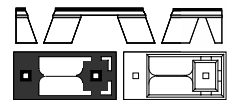

(e) Wet etching of $\mathrm{SiO}_{2}$

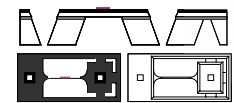

(f) Fabrication of grid pattern

$$
\overrightarrow{\mathrm{Si}} \quad \overline{\mathrm{SiO}_{2}} \quad \overline{\mathrm{DLC}} \quad \overline{\mathrm{Al}}
$$

Fig. 1 Fabrication process of DLC/SCS specimen along with the photograph.

investigation of the effects of film thickness and deposition condition on mechanical properties of sub-micron thick DLC films. Table 1 lists averaged dimensions of SCS and DLC/SCS specimens, along with the deposition condition of DLC films. Three samples for each deposition condition were used in the tests (total of 24 samples for DLC/SCS specimen).

\subsection{Development of tensile tester operating in AFM}

Figs. 2 (a)-(c) shows a schematic diagram and photographs of compact tensile tester developed in this research. As illustrated in Fig. 2(a), the tensile tester consists of PZT actuator, actuator case, load cell, linear variable displacement transducer (LVDT) and specimen holders. The PZT actuator possessing a resolution of 1 $\mathrm{nm}$ applies tensile force to a specimen hooked on the specimen holders. The actuator case has a hinge structure that can enlarge the actuator elongation to two times along the tensile direction of a specimen. The load cell and the LVDT, having the resolutions of $39 \mathrm{mg}$ and 10 $\mathrm{nm}$, respectively, can measure the tensile force and the relative displacement between the specimen holders. The tensile tester equipped with this setup is built in an AFM (Seiko Instrument Inc., NPX100) in order to measure the elongation at the gauge section of a specimen, directly (Fig. 2 (b) and (c)).

Fig. 3 is AFM image of a resist grid patterned on the gauge section of DLC/SCS specimen. The AFM observes the grid profile during a tensile test, so that longitudinal and lateral strains of the specimen can be calculated from the relative displacement between two lines of the grid facing each other. SCS and DLC/SCS specimens are fixed mechanically to specimen holders by hooking up

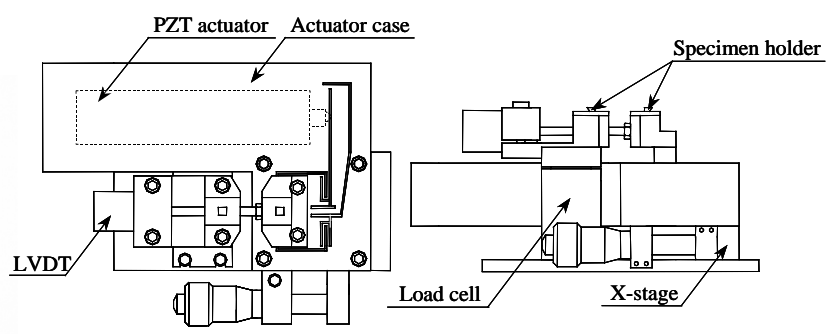

(a) Schematic of compact tensile tester

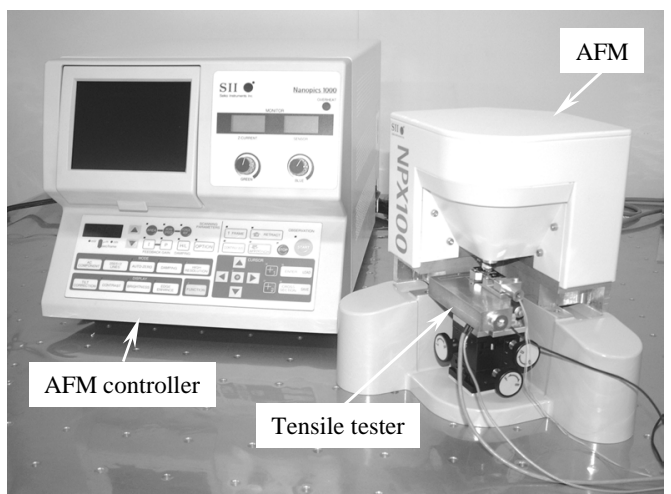

(b) Compact tensile tester built in AFM

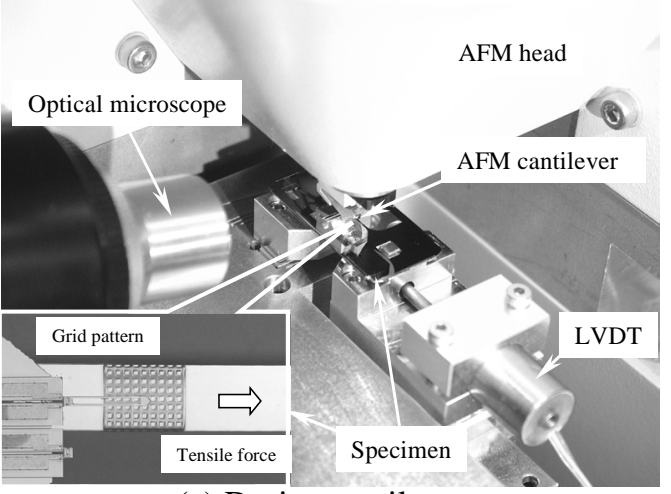

(c) During tensile test

Fig. 2 Compact tensile tester operating in AFM.

two square holes fabricated in both grip ends of the specimen. After settling the specimen on the tester and breaking three supported strips at the grip end, the tensile tests are carried out.

\subsection{Evaluation technique of mechanical properties for DLC film}

Young's modulus and Poisson's ratio of SCS specimens are calculated from the change of the resist 


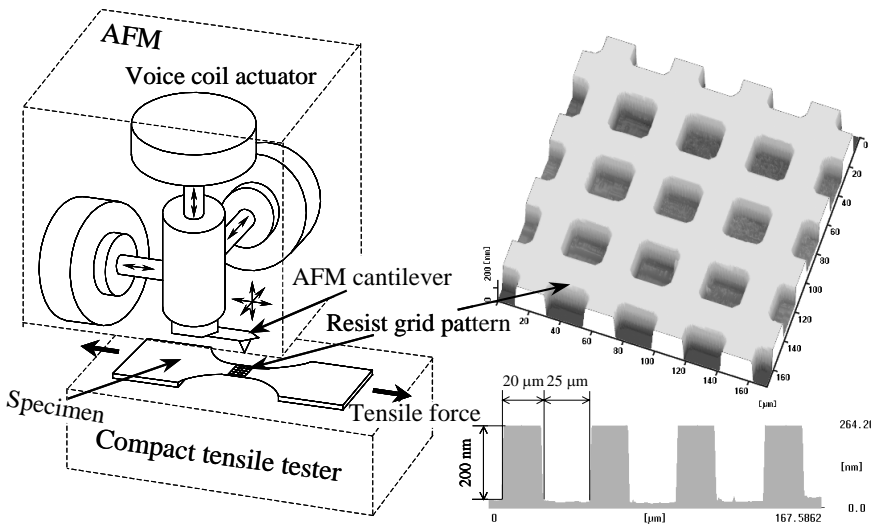

Fig. 3 AFM image of resist grid pattern.

grid pattern during tensile tests. Young's modulus of DLC films coated on SCS specimens is also derived from a resultant modulus, $E_{1+2}$. The $E_{1+2}$ is defined as the following equation, on the assumption that the longitudinal strain of DLC film is equal to that of SCS substrate due to the same fixed condition between the film and the substrate.

$$
E_{1+2}=\frac{t_{1} E_{1}+t_{2} E_{2}}{t_{1}+t_{2}}
$$

where, $E_{1}$ and $t_{1}$ are Young's modulus and thickness of SCS substrate, $E_{2}$ and $t_{2}$ are those of DLC film, respectively.

Young's modulus of DLC film can be determined by Eq. (1) if $E_{1+2}$ and $E_{1}$ are measured in the tensile test. However, Poisson's ratio of DLC film is not obtained from the tensile test even if the AFM can measure the longitudinal and lateral elongations on the top surface of the DLC/SCS specimen. This is caused by disagreement in the lateral strain between the DLC film and SCS substrate. In order to determine Poisson's ratio of DLC films, not only the tensile test but also nano-indentation test using a diamond indenter were performed. The nano-indentation test can measure a reduced modulus, $E_{r}$, from unloading stiffness of load-penetration depth curve. In this research, the indentation tests for $2 \mu \mathrm{m}$-thick DLC film coated on $400 \mu$ m-thick SCS substrate were carried out by following test procedure proposed by W. C. Oliver et al [8]. The unloading stiffness, $S$, corresponding to the gradient of the unloading curve, is formulated as

$$
\frac{1}{S}=C_{f}+\frac{\sqrt{\pi}}{2 E_{r}} \frac{1}{\sqrt{A}}
$$

where, $C_{f}$ is the compliance of load frame in nano-indentation tester, $E_{r}$ is reduced modulus, and $A$ is the contact area between the film and indenter.

The compliance of load frame must be calibrated prior to the indentation test. $E_{r}$ is also expressed by the sum of plane-strain moduli of the film and indenter as the following equation:

$$
\frac{1}{E_{r}}=\frac{\left(1-v_{2}^{2}\right)}{E_{2}}+\frac{\left(1-v_{i}^{2}\right)}{E_{i}}
$$

where, $v_{2}$ and $v_{i}$ are Poisson's ratio of DLC film and a diamond indenter, respectively, and $E_{i}$ is Young's modulus of the indenter.

The plane-strain modulus of the indenter can be calibrated by the indentation test using a material of which mechanical properties are already known. If $E_{r}$ is determined experimentally in the nano-indentation test, the Poisson's ratio, $v_{2}$, of the DLC film is calculated by applying the Young's modulus of the film and plane-strain modulus of the indenter to Eq. (3). This research used a commercial tester (SHIMADZU $^{\mathrm{TM}}$, DUH-200) in the tests.

\section{EXPERIMENTAL RESULTS}

\subsection{Results of AFM tensile tests}

Fig. 4 (a) shows typical tensile stress-strain curves of SCS specimen. All specimens were tensioned to failure. Closed and open plots indicate longitudinal and lateral strains, respectively, obtained by the AFM direct measurement technique. The LVDT also measures the relative displacement between specimen holders depicted as the solid line. The dashed line indicates the revised stress-strain relation by finite element analyses (FEAs) shown in Fig. 4(b). The FEA calculated the longitudinal elongation at the gauge section of the specimen, and revealed that the elongation generated at the gauge section was 0.58 times the displacement applied to the total length of the specimen. The strain expressed as the dashed line is, therefore, 0.58 -fold of that of the solid line.

The SCS specimen has linear stress-strain relation until failure as shown in Fig. 4(a). From an abrupt drop of tensile stress, it follows that the SCS specimen exhibits brittle failure after elastic deformation. Young's modulus of the SCS specimen derived from the AFM measurement is $168.8 \mathrm{GPa}$, which is in good agreement with analytical value based on the anisotropic theory [9]. However, the Young's modulus calculated from the solid line is 83.16 GPa. Even the Young's modulus revised by the FEA is $143.9 \mathrm{GPa}$, which is $17 \%$ smaller than the analytical value. The difference in the modulus may be produced by a narrow gap between the specimen and the holder. Poisson's ratio of the SCS obtained from the AFM measurement at the top surface, 0.069 , is also equivalent to analytical value; 0.064 . The tensile strength of the SCS is $1.53 \mathrm{GPa}$, which is also roughly identical to that in a previous paper [10]. Therefore, the direct measurement technique of elongation by an AFM is accurately able to evaluate Young's modulus, Poisson's ratio and fracture strength of a micro-scaled self-standing SCS specimen.

Fig. 5 (a) and (b) shows typical tensile stress-strain relations of DLC/SCS specimens deposited at the bias voltages of $-100 \mathrm{~V}$ and $-300 \mathrm{~V}$, respectively. DLC/SCS specimens exhibit linear stress-strain relations and abrupt reductions of the stress, whereby the specimens have fractured in a brittle manner. In Fig. 5(a), the resultant modulus, $E_{1+2}$, of the DLC/SCS specimen deposited at 
Table 2 Summary of experimental results of AFM tensile tests and nano-indentation tests.

\begin{tabular}{|c|c|c|c|c|c|c|c|c|}
\hline \multirow{4}{*}{\multicolumn{2}{|c|}{ Specimen No. }} & \multicolumn{5}{|c|}{ AFM tensile test } & \multicolumn{2}{|c|}{ Nano-indentation test } \\
\hline & & \multicolumn{2}{|c|}{ Young's moduli } & \multirow{2}{*}{$\begin{array}{c}\text { Poisson's ratio } \\
\text { DLC/SCS }\end{array}$} & \multicolumn{2}{|c|}{ Fracture strength } & \multirow{2}{*}{$\begin{array}{c}\text { Reduced modulus } \\
\text { DLC }\end{array}$} & \multirow{2}{*}{$\begin{array}{c}\text { Poisson's ratio } \\
\text { DLC }\end{array}$} \\
\hline & & DLC/SCS & DLC & & DLC/SCS & DLC & & \\
\hline & & $E_{1+2}[\mathrm{GPa}]$ & $E_{2}[\mathrm{GPa}]$ & $v_{A F M}$ & $\sigma_{1+2}[\mathrm{GPa}]$ & $\sigma_{2}[\mathrm{GPa}]$ & $E_{r}[\mathrm{GPa}]$ & $v_{2}$ \\
\hline SCS & & $\overline{169.00\left(E_{1}\right)}$ & - & 0.0695 (SCS) & $1.460\left(\sigma_{1}\right)$ & - & - & - \\
\hline \multirow{8}{*}{ DLC/SCS } & $A$ & 168.51 & 99.39 & 0.0742 & 1.362 & 0.803 & 104.68 & 0.362 \\
\hline & $B$ & 168.03 & 102.04 & 0.0775 & 1.175 & 0.714 & 104.68 & 0.328 \\
\hline & $C$ & 167.75 & 104.32 & 0.0818 & 1.249 & 0.777 & 104.68 & 0.296 \\
\hline & $D$ & 167.38 & 101.57 & 0.0835 & 1.049 & 0.634 & 104.68 & 0.333 \\
\hline & $E$ & 168.45 & 122.92 & 0.0804 & 1.082 & 0.790 & 128.11 & 0.374 \\
\hline & $F$ & 168.19 & 122.67 & 0.0849 & 0.996 & 0.726 & 128.11 & 0.376 \\
\hline & $G$ & 167.90 & 117.83 & 0.0916 & 0.839 & 0.590 & 128.11 & 0.419 \\
\hline & $H$ & 167.69 & 120.26 & 0.0953 & 0.820 & 0.586 & 128.11 & 0.396 \\
\hline
\end{tabular}

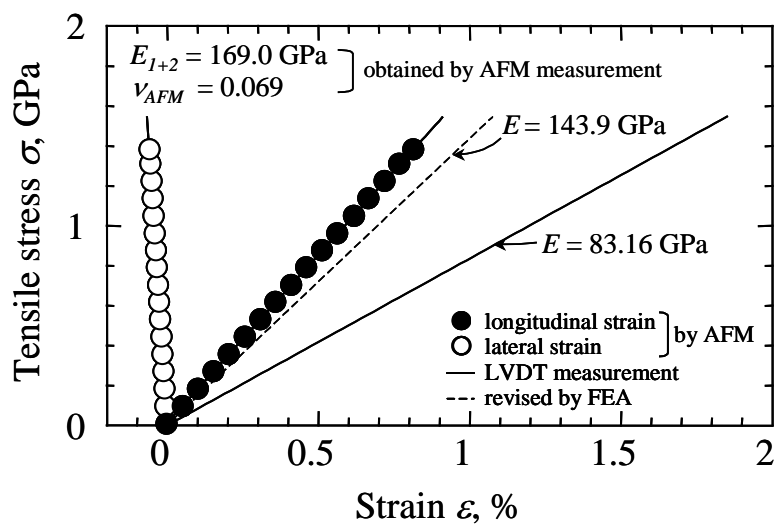

(a) Typical stress-strain curves of SCS specimen

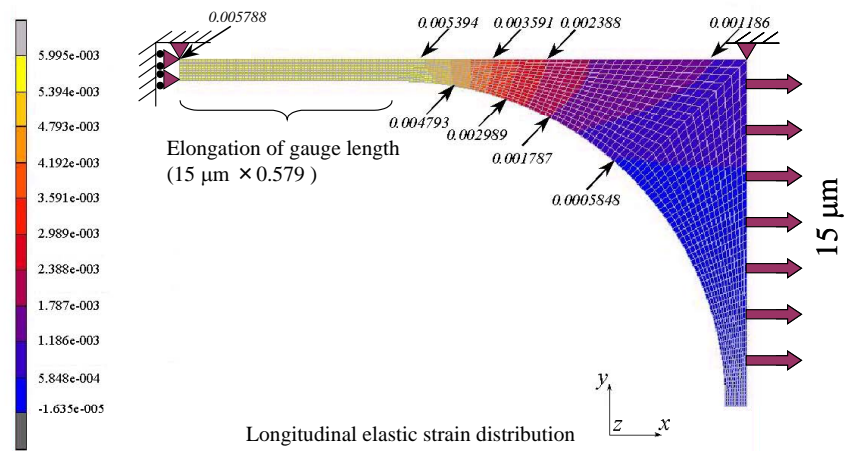

(b) Longitudinal elastic strain distribution by FEA

Fig. 4 Results of AFM tensile test and FEA for SCS specimen.

$-100 \mathrm{~V}$ is $168.5 \mathrm{GPa}$, which is close to the Young's modulus of SCS substrate. Inserting the resultant modulus into Eq. (1), we have found that Young's modulus of the DLC film is $100.5 \mathrm{GPa}$. As shown in Fig. $5(\mathrm{~b})$, the resultant modulus of the DLC/SCS specimen deposited at $-300 \mathrm{~V}$ is $168.6 \mathrm{GPa}$, which have led Young's modulus of the film to be $121.8 \mathrm{GPa}$. Poisson's ratios, $v_{A F M}$, of the DLC/SCS specimens measured on the top surface by the AFM are 0.074 and 0.079 , respectively. However, these ratios deviate from real values of DLC films since the lateral strain of the substrate is not equal to that of the film. Therefore, this research has calculated Poisson's ratio of the DLC films from their plane-strain modulus obtained in a nano-indentation test.

\subsection{Mechanical Properties of DLC films}

Table 2 summarizes averaged Young's modulus, Pois-

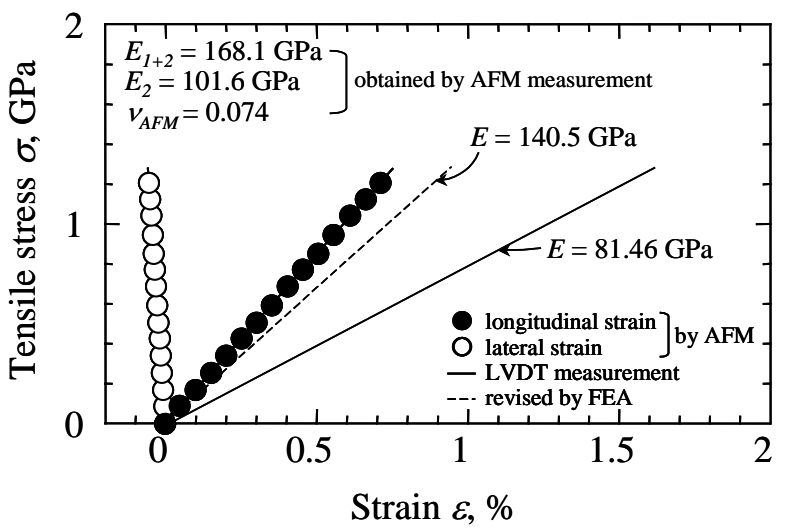

(a) $B_{v}=-100 \mathrm{~V}$

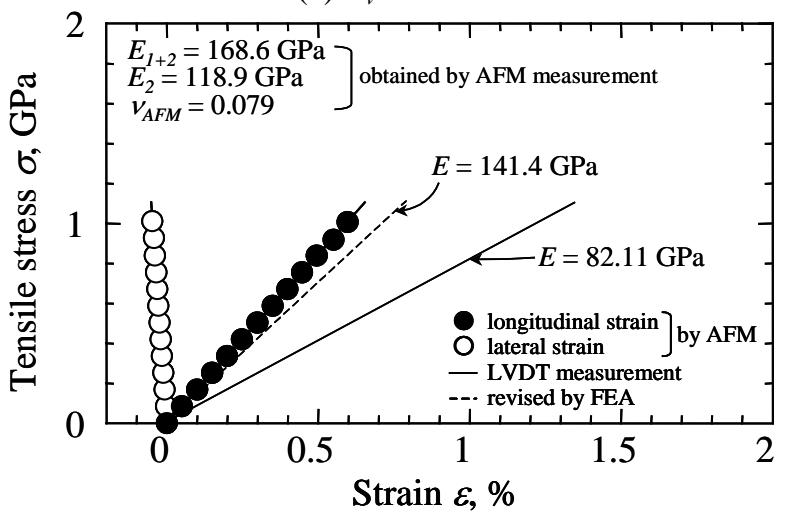

(a) $B_{v}=-300 \mathrm{~V}$

Fig. 5 Typical stress-strain curves of DLC/SCS specimen.

son's ratio and fracture strength of the SCS and DLC films obtained from AFM tensile tests and nano-indentation tests. Young's moduli of DLC films deposited at $-100 \mathrm{~V}$ and $-300 \mathrm{~V}$ average $101.8 \mathrm{GPa}$ and $120.9 \mathrm{GPa}$, respectively, which are slightly smaller than reduced moduli obtained from nano-indentation tests. Averaged Poisson's ratio, $v_{2}$, of DLC films deposited at $-100 \mathrm{~V}$ ranges from 0.296 to 0.362 . These are quite different from the ratio, $v_{A F M}$, obtained by the AFM direct measurement of DLC/SCS specimen. The difference in the ratio is produced by the restriction of lateral deformation in DLC film on SCS substrate during tensile loading. This is because of small Poisson's ratio of the SCS oriented to the [110] direction in the (001) plane. The Poisson's ratio of DLC film deposited at $-300 \mathrm{~V}$ also exhibits larger values ranging from 0.374 to 0.419 , as 


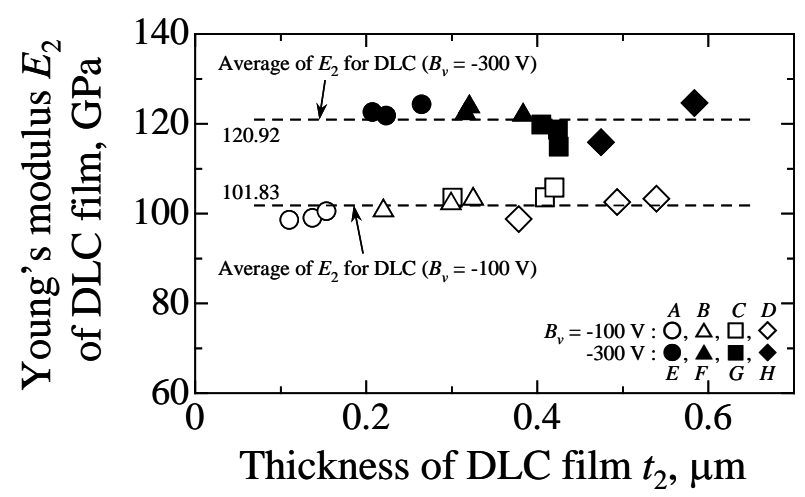

(a) Young's modulus vs. film thickness

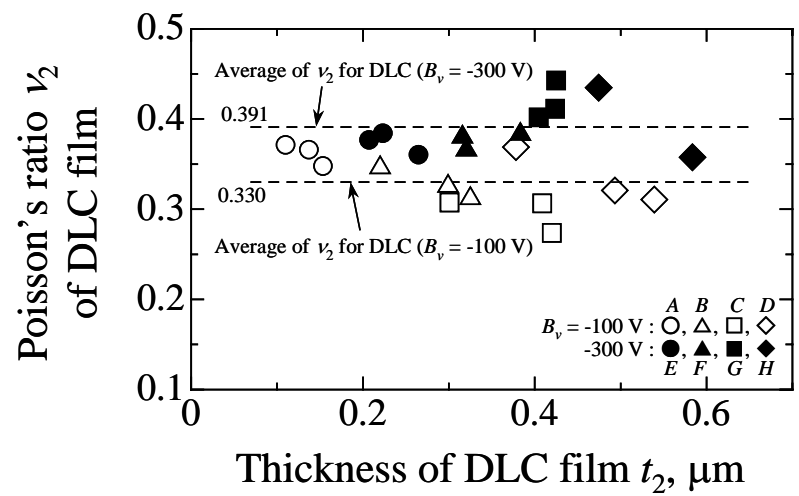

(b) Poisson's ratio vs. film thickness

Fig. 6 Relations of Young's modulus and Poisson's ratio of DLC film to the thickness.

compared with the ratio derived from the AFM measurement.

Fig. 6 (a) and (b) shows variations of Young's modulus and Poisson's ratio of DLC films with increasing the film thickness, respectively. Averaged Young's modulus of DLC films deposited at $-100 \mathrm{~V}$ exhibits $101.8 \mathrm{GPa}$, regardless of film thickness over the entire thickness range used in this research (Fig. 6 (a)). The averaged modulus of DLC films deposited at $-300 \mathrm{~V}$ also indicates a constant value of $120.9 \mathrm{GPa}$, which is 1.18 times that of DLC films deposited at $-100 \mathrm{~V}$. The relation of Poisson's ratios of DLC films to the film thickness shows a trend similar to that exhibited by Young's modulus to the thickness (Fig. 6 (b)), although data scatter exists. The averaged Poisson's ratios of DLC films deposited at -100 $\mathrm{V}$ and $-300 \mathrm{~V}$ indicate 0.33 and 0.39 , respectively, and are also in the ratio of $1: 1.18$. Owing to the change of hydrogen content in DLC films by the deposition condition [11], the bias voltage set during the PE-CVD would have influenced elastic properties of the films.

\subsection{Fracture mechanism of DLC/SCS specimen}

Fig. 7 shows the relationship between fracture strength of DLC films and film thickness. Fracture strength of DLC film was calculated from multiplying the maximum longitudinal strain of DLC/SCS specimen just before the fracture by Young's modulus of the film. The fracture strength of DLC films ranges from $0.51 \mathrm{GPa}$ to $1.03 \mathrm{GPa}$, and decreases with increasing the film thickness. The difference in the strength between DLC films deposited at $-100 \mathrm{~V}$ and $-300 \mathrm{~V}$ does not clearly exist; therefore, the

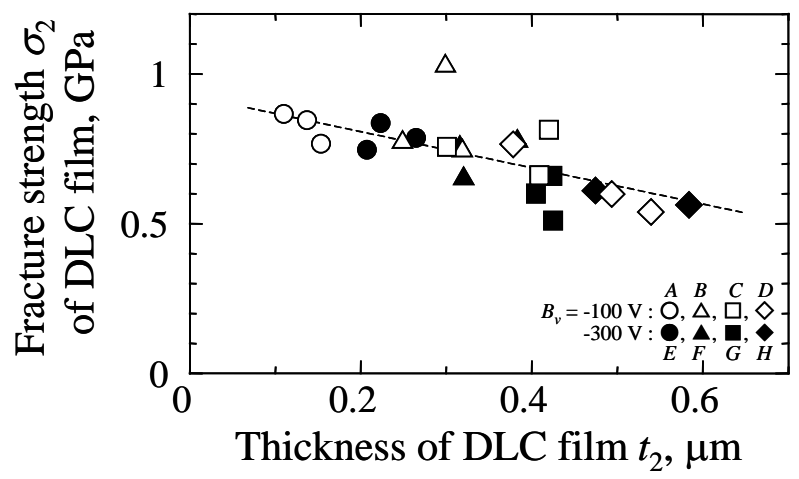

Fig. 7 Fracture strength of DLC film as a function of the thickness.

fracture strength is independent of deposition condition whereas it is influenced by film thickness. Fig. 8 (a)-(c) shows SEM photographs of fracture surfaces of DLC/SCS specimens deposited at $-100 \mathrm{~V}$. The greater part of the fracture surface is smooth, due to a cleavage of SCS substrate (Fig. 8(a)). In Fig. 9(b), however, a semicircular crack is seen at the boundary between DLC film and substrate. The river pattern generated from the boundary is also observed at the right side of the semicircular crack (Fig. 8(c)). Also, the specimen did not have any latent defects at the top surface and the inside; therefore, the fracture of the DLC/SCS specimen deposited at $-100 \mathrm{~V}$ would have initiated at the film/substrate boundary. Fracture of DLC/SCS specimen deposited at $-300 \mathrm{~V}$ was also produced at film/substrate boundary, although the photograph of the fracture surface is omitted here. DLC film produced by PE-CVD process is known to be a material possessing residual compressive stress, due to the difference of thermal expansion coefficient between the film and a substrate [12]. Supposing the compressive stress is independent of film thickness, the difference in strain between DLC film and substrate increases with increasing the film thickness; thereby leading the film to be peeled or lifted off easily at the boundary. Therefore, the fracture initiation of DLC/SCS specimens was induced conceivably at the boundary. However, the essence of the fracture of DLC/SCS specimen cannot be concluded until further evaluations of residual stress and stress/strain distribution in the specimen have been performed.

\section{CONCLUSION}

We developed compact tensile tester operating in an AFM for mechanical characterization of the SCS specimens and sub-micron thick DLC films. The AFM tensile test can accurately evaluate mechanical properties of micro-scaled self-standing SCS specimens. The tensile and nano-indentation combined tests also exhibited effectiveness for mechanical characterization of the DLC films with thickness of 0.11 to $0.58 \mu \mathrm{m}$. Young's moduli of the DLC films coated at bias voltages of $-100 \mathrm{~V}$ and $-300 \mathrm{~V}$ ranged from 99.4 GPa to 104.3 GPa and from 117.8 $\mathrm{GPa}$ to $122.9 \mathrm{GPa}$, respectively. Poisson's ratios of the films averaged 0.33 for $-100 \mathrm{~V}$ and 0.39 for $-300 \mathrm{~V}$; therefore, elastic properties of DLC films had an effect on negative bias voltage, but are independent of film thickness. FEAs for DLC/SCS specimens also revealed 


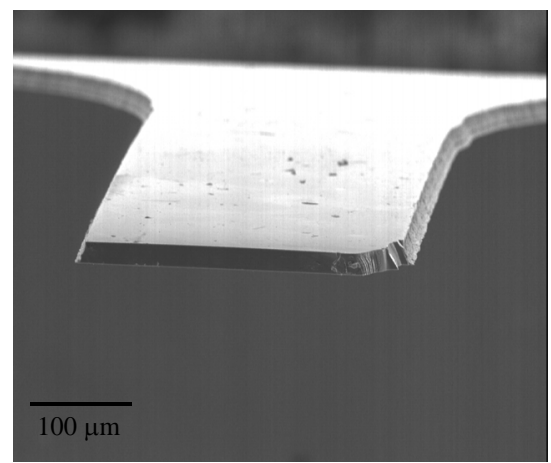

(a) Cleavage fracture surface of DLC/SCS specimen

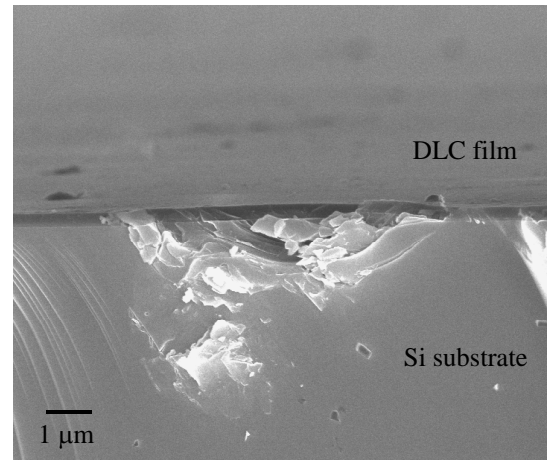

(b) Semicircular crack at boundary between film and substrate

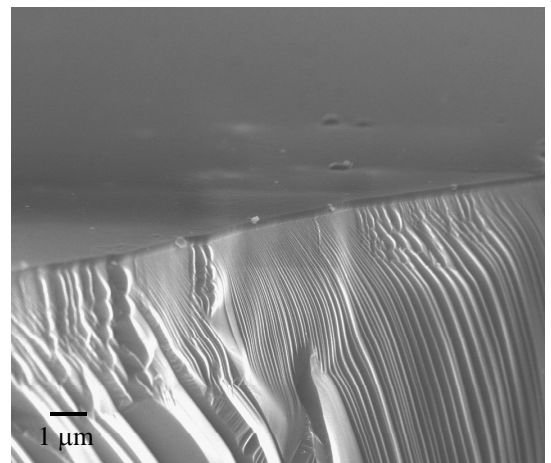

(c) River pattern generated from boundary between film and substrate

Fig. 8 SEM micrographs of fracture surfaces for DLC/SCS specimen $\left(B_{v}=-100 \mathrm{~V}\right)$

that the evaluation technique presented in this research showed good potential for the sub-micron thick film coated on SCS substrate. Fracture strength of the DLC films ranged from $0.51 \mathrm{GPa}$ to $1.03 \mathrm{GPa}$, which decreased with increasing the film thickness. However, the fracture strength did not depend on deposition condition. SEM observations of the fracture surface suggested that the fracture initiation of DLC/SCS specimens was induced at the material interface, due to the difference in strain between the film and substrate.

\section{REFERENCES}

1. H. O. Pierson, Handbook of Carbon, Graphite, Diamond and Fullerenes, Piscataway, NJ: Noyes Publications (1993).

2. K. Komovopoulos, "Surface engineering and micro-tribology for micro electromechanical systems", Wear, vol. 200 (1996) p. 205.

3. J. Robertson, Surf. Coat. Technol., vol. 50 (1992), p. 285.

4. B. Bhushan, "Nanoscale tribophysics and trobomechanics", Wear, vol. 255, no. 1 (1999), p. 465.

5. V. Prabhakaran and E. F. Talke, "Wear and hardness of carbon overcoats on magnetic recording sliders", Wear, vol. 243, no. 1 (1999), p. 18

6. A. Richter, R. Ries, R. Smith and M. Henkel, "Nanoindentation of diamond, graphite and fullerene films",
Diamond and Related Materials, vol. 9, no. 2 (2000), p. 170.

7. Y. Isono, T. Namazu, T. Tanaka and N. Terayama, "Mechanical Characterization of Sub-Micrometer Thick DLC Films by AFM Tensile Testing for Surface Modification in MEMS", Proc. Microelectromechanical Systems (2002), p.431.

8. W. C. Oliver and G. M. Pharr, "An improved technique for determining hardness and elastic modulus using load and displacement sensing indentation experiments", J. Mater. Res., vol. 7, no. 6 (1992), p. 1564.

9. H. J. McSkimin, "Measurement of Elastic Constants at Low Temperatures by Means of Ultrasonic Waves Data for Silicon and Germanium Single Crystals, and for Fused Silica", J. Appl. Phys., vol. 24, no. 8 (1953), p. 988.

10. T. Namazu, Y. Isono and T. Tanaka, "Evaluation of size effect on mechanical properties of single crystal silicon by nanoscale bending test using AFM", J. Microelectromech. Syst., vol. 9, no. 4 (2000), p. 450.

11. M. A. E. Khakani, M. Chaker, A. Jean, S. Boily and J. C. Kieffer, J. Mater. Res., vol. 9 (1994), p. 96.

12. A. A. Ogwu, R. W. Ramberton, P. D. Maguire and J. A. McLaughlin, J. Phys. D, Appl. Phys., vol. 32 (1999), p. 981. 